\title{
A rotary reactor for thermal and plasma-enhanced atomic layer deposition on powders and small objects
}

\author{
Delphine Longrie $^{a}$, Davy Deduytsche ${ }^{a}$, Jo Haemers ${ }^{a}$, Kris Driesen $^{b}{ }^{,}$Christophe Detavernier $^{a}$ \\ ${ }^{a}$ COCOON, Department of Solid State Sciences, Ghent University, Ghent, Belgium \\ ${ }^{\mathrm{b}}$ Umicore, Olen, Belgium
}

\section{Introduction}

Possible applications for particles have strongly increased during the last decade. Many of these applications require particles to have different surface and bulk properties ${ }^{1-5}$ which can be achieved by e.g. coating the particles with a nanometer thick layer. The key challenge is in coating the individual particles with an ultrathin and conformal coating, which is especially difficult in the case of nanoparticles since they have a very large surface area and the tendency to coalesce.

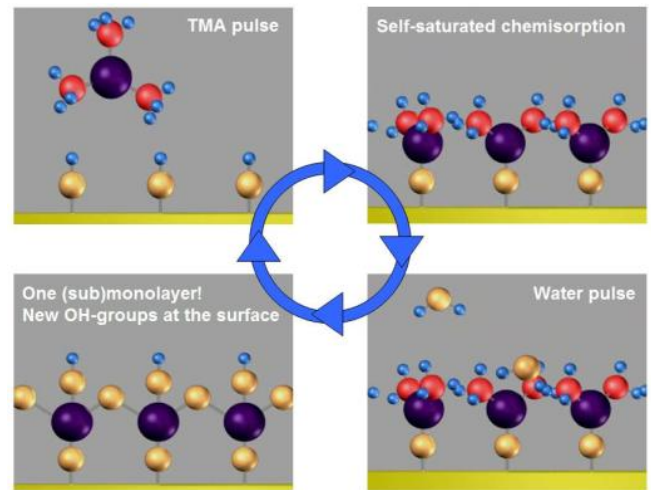

Fig. 1: $A L D$ cycle for growth of $\mathrm{Al}_{2} \mathrm{O}_{3}$ using $T M A$ as precursor and $\mathrm{H}_{2} \mathrm{O}$ as reactant. One complete $A L D$ cycle consists of a precursor pulse, pump time, a reactant pulse and pump time.
Atomic layer deposition (ALD) is a technique consisting of two sequential, self-limiting gas-phase surface reactions that enables deposition of ultrathin, conformal and uniform thin films ${ }^{6-8}$. Fig. 1 shows the ALD cycle for growth of $\mathrm{Al}_{2} \mathrm{O}_{3}$. During the first step of the ALD cycle, the $\mathrm{OH}$-terminated starting surface is exposed to a pulse of TMA (Trimethylaluminium). These precursor molecules will interact with the $\mathrm{OH}$ surface groups when binding to the surface, forming $\mathrm{CH}_{4}$ as reaction product. These $\mathrm{CH}_{4}$ molecules and any remaining TMA will be evacuated during the subsequent pump time. The reactant in the case of thermal ALD is $\mathrm{H}_{2} \mathrm{O}$. The $\mathrm{H}_{2} \mathrm{O}$ molecules will remove the remaining $\mathrm{CH}_{3}$ ligands and creating $\mathrm{CH}_{4}$ as reaction product, form $\mathrm{O}$-bonds between the $\mathrm{Al}$ atoms creating the $\mathrm{Al}_{2} \mathrm{O}_{3}$ layer and terminate the surface with $\mathrm{OH}$-bonds. The remaining $\mathrm{H}_{2} \mathrm{O}$ molecules and the formed $\mathrm{CH}_{4}$ will be evacuated during the subsequent pump time, leaving a new $\mathrm{OH}$-terminated surface for the next precursor pulse to react with. When performing PEALD, an $\mathrm{O}_{2}$-plasma replaces the $\mathrm{H}_{2} \mathrm{O}$ pulse. The oxygen radicals in the plasma will then remove the remaining $\mathrm{CH}_{3}$ groups on the $\mathrm{Al}$ atom in combustion-type reactions, creating $\mathrm{CO}_{2}$ and $\mathrm{H}_{2} \mathrm{O}$ as reaction products.

To enable the deposition of ALD coatings on large quantities of particles, fluidized bed reactors have been developed and proven for a variety of processes ${ }^{9-13}$. Since a gas flow is used to levitate the particles, a high gas throughput is required and only fine and light powders can be fluidized. Due to the high pressures inside these reactors, plasma-enhanced ALD (PEALD) will be impossible, limiting them to thermal ALD processes only. Furthermore, additional energy will be necessary (e.g. mixing, vibrations) when coating nanopowders due to their high interparticle forces which causes them to coalesce ${ }^{914-16}$. Finally, the use of a fluidizing gas also renders it impossible to use static reactant exposures to increase the efficiency of the process ${ }^{17}$ and minimize the usage of expensive precursors.

Therefore it is important to develop alternative ways of fluidizing nanopowders, particles and granules while enabling static reactant exposures. A method based on a rotating metal cylinder was proposed by McCormick et al. ${ }^{18-20}$ which traps the powder inside pores of a rotating metal cylinder. The particles are released when reaching the top of the rotation circle, thus being exposed to the reactant gas. While enabling depositions with static exposures, the use of a metal cylinder inside a stainless steel vacuum chamber still renders PEALD using an inductive coupled RF plasma impossible.

\section{Objectives}

In this paper a design for a rotary ALD reactor ${ }^{21-22}$ is presented that enables both thermal and plasmaenhanced ALD on large quantities of agitated particles. The agitation of the particles is achieved mechanically, thus no fluidizing gas is used. This makes it possible to coat particles ranging from nanometer sized powders to centimeter sized objects. The effectiveness of the reactor design will be demonstrated by depositing $\mathrm{Al}_{2} \mathrm{O}_{3}, \mathrm{TiO}_{2}$ and AIN by both thermal and plasma-enhanced ALD on $\mathrm{ZnO}$ 
nanopowder, stainless steel micron sized powder and titanium granules and glass beads. Saturation of the ALD half-reactions will be confirmed using in-situ optical emission spectroscopy (OES) and mass spectroscopy (MS) measurements. The composition and conformality of the deposited films will be verified by ex-situ X-ray fluorescence (XRF), X-ray photo-electron spectroscopy (XPS), energydispersive $X$-ray spectroscopy (EDX) and transmission electron microscopy (TEM) measurements.

\section{Methods}

\subsection{Rotary reactor}

The rotary reactor that will be described allows for the combination of static reactant exposures, working under high vacuum conditions $\left(10^{-5} \mathrm{mbar}\right)$ and mechanically agitating large quantities of particles ranging from (porous) nano sized powders $(<100 \mathrm{~nm}$ ) to small objects (up to $1 \mathrm{~cm}$ ). The reactor performs pump-type ALD reactions, so no purging is used. A diagram of the reactor design is shown in Fig. 2. The main chamber is a rotating quartz tube attached at both ends by a vacuum tight connection to a fixed metal frame. One end of the frame is connected to a gas inlet system consisting of a custom-made, multiple-input flange, while the other end is connected to a turbomolecular pump for evacuating the chamber and a mass spectrometer for performing gas analyses.

To enable switching between pulse-type ALD reactions and static reactant exposures, a pneumatic valve can be closed between the reactor chamber and the pumping system. This enables exposure of the particles to a predefined reactant pressure for any length of time while still mechanically agitating them. The particles are contained in the vacuum reactor chamber in an open glass tube which is placed inside the outer quartz tube and coupled to it. The powder is confined to a $15 \mathrm{~cm}$ sized zone of the inner tube by indentations narrowing the tube diameter. Along the length of this zone two grooves were made to mix the particles by making them tumble over the grooves.

The temperature of the particles inside the reactor is controlled by a tube furnace positioned around the outer quartz tube. This allows for accurate control of the deposition temperature within a wide range (up to $1000^{\circ} \mathrm{C}$ ). Upstream from the tube furnace a RF power generator $(13.56 \mathrm{MHz}$ ) is placed to ionize the reactant gas and enable PEALD. The RF generator is composed of an RF coil placed around the outer tube, a power supply and a matching unit. The reaction zone is downstream from the plasma region, making PEALD possible by ensuring the presence of radicals while minimizing the presence of high energy ions, thus avoiding physical bombardment and damage to the surface.

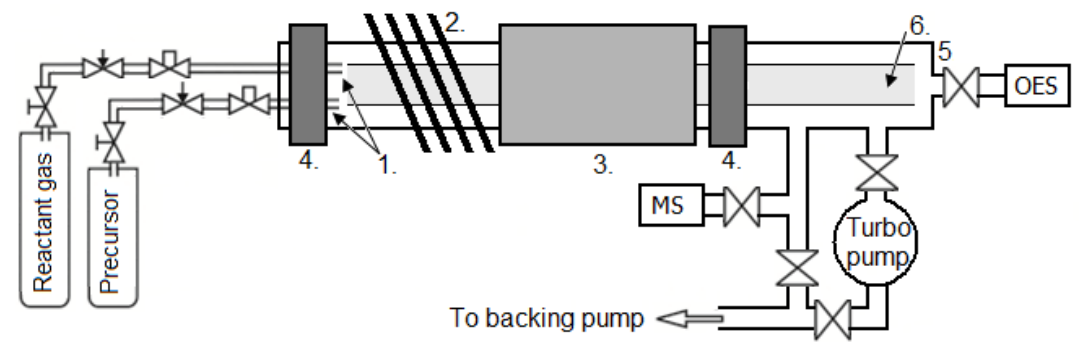

Fig. 2: Diagram of the rotary reactor:(1) inlets for gases, (2) RF coil, (3) tube furnace, (4) mechanical rotation system, (5) inlet for the inner dielectric tube and (6) inner tube containing the particles to be coated.

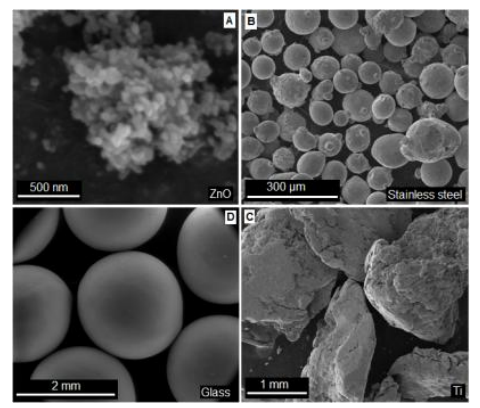

Fig. 3: SEM images of (A) ZnO powder, (B) stainless steel powder, (C) Ti granule and (D) glass beads.

\subsection{Experimental}

$\mathrm{Al}_{2} \mathrm{O}_{3}$ was deposited by thermal ALD with TMA $\left(1.5 \times 10^{-3} \mathrm{mbar}\right)$ and $\mathrm{H}_{2} \mathrm{O}\left(1.5 \times 10^{-3} \mathrm{mbar}\right)$ as reactants and by PEALD with TMA and an $\mathrm{O}_{2}$-plasma $\left(4 \times 10^{-4} \mathrm{mbar}, 200 \mathrm{~W}\right)$ as reactants. The reaction zone was heated to $200{ }^{\circ} \mathrm{C}$. $\mathrm{TiO}_{2}$ was deposited by thermal ALD with TDMAT (Tetrakis dimethylamino titanium) and $\mathrm{H}_{2} \mathrm{O}$ as reactants. Due to the low vapor pressure of TDMAT, argon was used as a carrier gas to reach a pressure of $1.5 \times 10^{-3} \mathrm{mbar}$ during the TDMAT pulse. The reaction zone was heated to $150^{\circ} \mathrm{C}$. AIN was deposited by thermal ALD with TMA and $\mathrm{NH}_{3}$ as reactants and by PEALD with TMA and an $\mathrm{NH}_{3}$-plasma $\left(4 \times 10^{-4}\right.$ mbar, $\left.200 \mathrm{~W}\right)$ as reactants. The reaction zone was heated to $100{ }^{\circ} \mathrm{C}$.

Depositions were performed on different types of powders (shown in Fig. 3): micron sized ZnO powder (BET: $3.9 \mathrm{~m}^{2} \mathrm{~g}^{-1}$ ) and nano sized $\mathrm{ZnO}$ powder (BET: $33.2 \mathrm{~m}^{2} \mathrm{~g}^{-1}$ ), smooth and spherical micron sized stainless steel powder (from $45 \mu \mathrm{m}$ to $125 \mu \mathrm{m}$ ), rough and irregular titanium granules (from $0.2 \mathrm{~mm}$ to $1.5 \mathrm{~mm}$ ) and smooth and spherical glass beads (particle diameter $2 \mathrm{~mm}$ ). 
In-situ MS (HAL 7 RC RGA 511\#3203, Hiden analytical) measurements were performed using the spectrometer in Multiple Ion Detection mode and Bar Scan mode using the Faraday detector (source voltage $70 \mathrm{~V}$ ). In-situ OES (Ocean Optics QE65000, int. time $100 \mathrm{~ms}$ ) measurements were also performed. The composition and conformality of the ALD coatings were verified using EDX (Quanta 200F, FEI), TEM (Tecnai G2, $200 \mathrm{kV}$ ), XPS (Surface Science Instruments, monochromatic Al Ka radiation) and XRF (Artax, Bruker, silicon drift detector, angle $52^{\circ}$, real time $100 \mathrm{~s}$ ) using simultaneously $\mathrm{Cu} \mathrm{K}_{\alpha}$ (angle $15^{\circ}, 40 \mathrm{kV}, 40 \mathrm{~mA}$ ) and $\mathrm{Mo} \mathrm{K}_{\alpha}$ radiation (angle 45, $12 \mathrm{kV}, 120 \mu \mathrm{A}$ ).

\section{Results}

\subsection{Thermal ALD}

Three different amounts of $\mathrm{ZnO}$ powder area were coated thermally with $\mathrm{Al}_{2} \mathrm{O}_{3}$ while the formation of the reaction product $\mathrm{CH}_{4}$ was measured using MS. Tracking the formation of $\mathrm{CH}_{4}$ as function of time during the reactant $\left(\mathrm{H}_{2} \mathrm{O}\right)$ pulse makes it possible to determine saturation of the surface reactions. The formation of $\mathrm{CH}_{4}$ starts simultaneously with the reactant pulse (see Fig. 4), confirming fast reactions between the reactant gas and the powder surface. The $\mathrm{CH}_{4}$ signal quickly reaches a maximum and will remain constant as long as the maximal amount of surface reactions occur. When the amount of reactive powder surface decreases, the partial pressure of $\mathrm{CH}_{4}$ will decrease as a result of fewer surface reactions occurring and evacuation of the reaction products through pumping. There is a linear relationship between the necessary pulse time for saturation and the surface area of powder present inside the reactor. The rather long pulse times found experimentally are due to the low pressures used and can be significantly reduced by increasing the reactant pressure. XPS measurements confirmed the composition of the layer, while TEM images (Fig. 5) show that all individual $\mathrm{ZnO}$ grains were uniformally coated with a conformal $5 \mathrm{~nm}$ ( 50 ALD cycles, $1 \AA$ A/ cycle) thick amorphous $\mathrm{Al}_{2} \mathrm{O}_{3}$ layer.

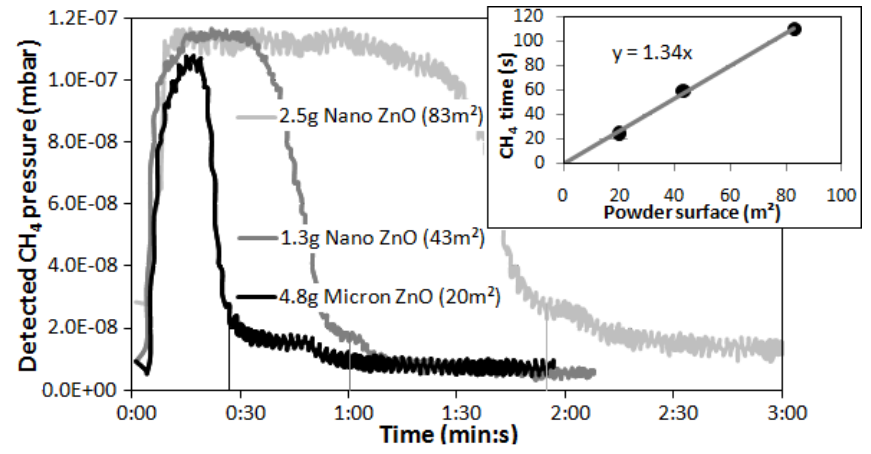

Fig. 4: $\mathrm{CH}_{4}$ partial pressure as function of time during the $\mathrm{H}_{2} \mathrm{O}$ pulse for different amounts of $\mathrm{ZnO}$ powder in the reactor and (inset) linear relationship between the $\mathrm{CH}_{4}$ detection time and the powder surface.

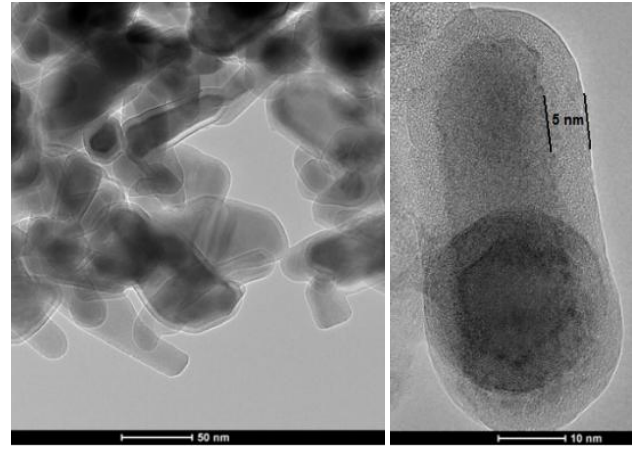

Fig. 5: TEM image of ZnO nano sized powder coated with $5 \mathrm{~nm}$ (50 cycles) amorphous $\mathrm{Al}_{2} \mathrm{O}_{3}$.

Besides the deposition of conformal and uniform layers, a marked advantage of ALD as a thin film deposition technique is the precise control over the thickness of the grown layers. Every ALD cycle, the same amount of material is deposited $\left(0.5 \AA /\right.$ cycle for the $\mathrm{TiO}_{2}$ process), allowing for a linear relationship between the thickness of the grown layer and the amount of cycles deposited. XRF was used to confirm linearity of the thermal $\mathrm{TiO}_{2}$ process by coating $\mathrm{ZnO}$ nano sized powder with different numbers of ALD and measuring each sample with XRF. Fig. 6 shows the increase in the titanium peak at $4.512 \mathrm{keV}$ in the subsequent XRF spectra, corresponding to larger amounts of titanium on the powder surface. The inset proves the linear relationship between the ratio of the titanium-to-zinc signal and the number of ALD cycles deposited, confirming that the ALD process leads to linear growth.

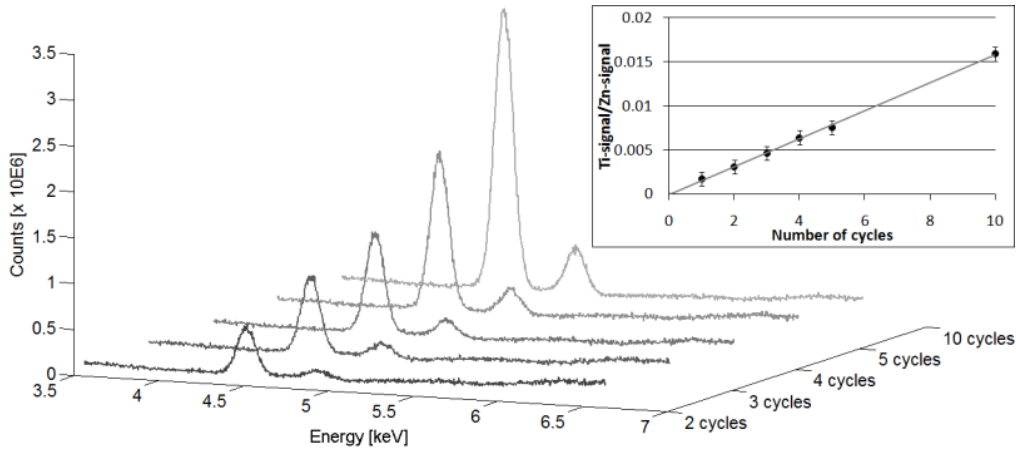

Fig. 6: Evolution of the titanium XRF-peak $(4.512 \mathrm{keV})$ as function of the number of $\mathrm{TiO}_{2}$ ALD cycles deposited and (inset) ratio of the Ti-to-Zn XRF-signal as function of the number of $\mathrm{TiO}_{2} \mathrm{ALD}$ cycles on $\mathrm{ZnO}$ nanopowder. 


\subsection{Plasma-enhanced ALD}

One advantage of this reactor design is that it is possible to coat particles using PEALD. During plasma processes, OES becomes available as a detection tool in addition to MS. OES measurements can detect the formed reaction products during the plasma pulse of the ALD cycle. For PEALD of $\mathrm{Al}_{2} \mathrm{O}_{3}$ these reaction products are $\mathrm{CO}_{2}$ and $\mathrm{H}_{2} \mathrm{O}$ and they are visible in the OES spectra as $\mathrm{CO}^{*}, \mathrm{OH}^{*}$ and $\mathrm{H}^{*}$ emissions due to the excitation of $\mathrm{CO}_{2}$ and $\mathrm{H}_{2} \mathrm{O}$ molecules by electron impact. Comparable to MS saturation measurements, the formation of the reaction products $\mathrm{CO}^{*}$ and $\mathrm{H}^{*}$ in the OES spectra was monitored for different amounts of powder inside the reactor. These measurements showed that an increase in powder mass inside the reactor leads to a longer detection time for the formed reaction products, confirming that a longer time is needed to saturate the surface reactions. The saturation time is linearly dependent on the powder mass present, as is the case for thermal ALD processes. MS measurements were performed simultaneously and confirm the saturation times found with OES.

The chief advantage of PEALD is that it enables growth under circumstances where thermal ALD is not possible, e.g. at low substrate temperatures. This is illustrated by the deposition of 50 cycles of AIN on $\mathrm{ZnO}$ nanopowder using both the thermal and the plasma-enhanced ALD process at $100{ }^{\circ} \mathrm{C}$. This substrate temperature is below the temperature window for the thermal process, thus no thermal growth occurs, while AIN is grown with the PEALD process, as shown in Fig. 7. These depositions were also performed successfully (confirmed by EDX and XPS) on the other particles mentioned.

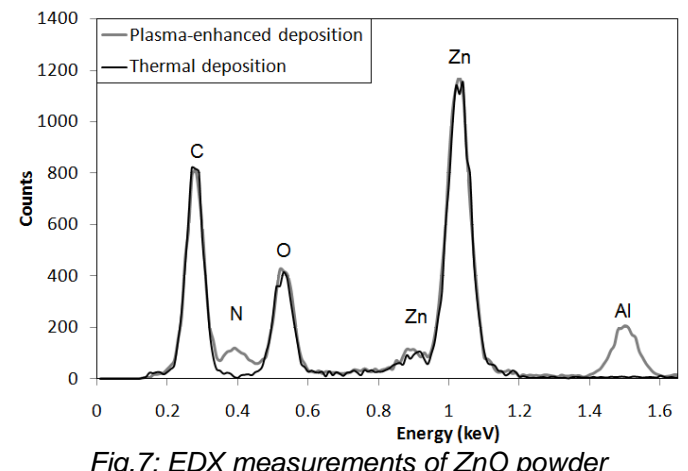

Fig.7: EDX measurements of ZnO powder coated with 50 cycles of AlN deposited with the thermal and plasma-enhanced processes.

\section{Conclusions}

A rotary reactor for thermal and plasma-enhanced ALD on agitated particles has been developed. The mechanical agitation is performed to reduce the necessary exposure time to the precursor gases and to allow coating the individual particles instead of larger agglomerates. The reactor can be used for both pump-type ALD reactions and static exposures, which leads to a more efficient usage of reactant gases. A first advantage of this reactor design is the possibility of performing PEALD, which allows growth of very pure ALD layers under circumstances where thermal ALD is not possible. A second advantage is the large variety of agitated particles that can be coated: from nano sized powders under $100 \mathrm{~nm}$ up to particles and small objects up to $1 \mathrm{~cm}$. The performance of this reactor design was illustrated by deposition of $\mathrm{Al}_{2} \mathrm{O}_{3}, \mathrm{TiO}_{2}$ and $\mathrm{AIN}$ by thermal and plasma-enhanced ALD on a variety of particle substrates: $\mathrm{ZnO}$ micron and nano sized powder, smooth stainless steel micron sized powder, rough and irregularly shaped titanium granules and larger glass beads. In-situ OES and MS measurements allowed for the precise determination of the pulse times needed for saturation, while XRF measurements confirmed linearity of the ALD process and deposition of AIN at $100^{\circ} \mathrm{C}$ illustrated PEALD growth. By successfully depositing different ALD layers on particles varying greatly in size, composition and shape it was demonstrated that the reactor has a wide potential range of applicability. The TEM, XPS, XRF and EDX results on the coated and uncoated particles indicate that the deposited layers that were tested were conformal, uniform and believed to be pinhole free.

\section{References}

1. J.D. Ferguson et al., Powder Technol. 156 (2005) 154 2. N. Avci et al., J. Electrochem. Soc. 156 (2009) 333

3. D.M ; King et al., J. Electrochem. Soc. 25 (2009) 163

4. D.M. King et al., Adv. Funct. Mater. 18 (2008) 607

5. M.Q. Snyder et al., J. Power Sources 165 (2007) 379

6. S.M. George, Chem. Rev. (2010), 110

7. C. Detavernier et al., Chem. Soc. Rev. (2011), 40 (11)

8. M. Kentz et al., 2012, ISBN 9783527327973

9. D.M. King et al., ECS Trans. 25 (2009) 163

10. J.R. Wank et al., Powder Technol. 142 (2004) 59

11. X.H. Liang et al., J. Membr. Sci. 322 (2008) 105
12. X.H. Liang et al., Nanothechnology 19 (2008)

13. L.F. Hakim et al., Diam. Relat. Mater. 17 (2008) 185

14. J.R. Wank et al., Powder Technol. 121 (2001) 195

15. L.F. Hakim et al., Powder Technol. 160 (2005) 149

16. L.F. Hakim et al., Chem. Eng. Sci. 62 (2007) 6199

17. J. Dendooven et al., J. Electrochem. Soc. 156 (2009) 63

18. J.A. McCormick et al., J. Vac. Sci. Technol. A25 (2007) 67

19. J.A. McCormick et al., Chem. Vap. Depos. 13 (2007) 491

20. A.S. Cavanagh et al., Nanotechnology 20 (2009)

21. C. Detavernier et al., WO 2010/046373

22. D. Longrie et al., Surf. Coat. Tech. 213 (2012) 183 